\title{
Material Processing with a 3kW Single Mode Fibre Laser
}

\author{
Lars HARTWIG ${ }^{* 1}$, Robby EBERT ${ }^{* 1}$, Sascha KLOETZER ${ }^{* 1}$, Sebastian WEINHOLD ${ }^{* 1}$, \\ Jan DRECHSEL ${ }^{* 1}$, Frank PEUCKERT ${ }^{* 1}$, Joerg SCHILLE ${ }^{* 1}$ and Horst EXNER ${ }^{* 1}$ \\ ${ }^{* 1}$ University of Applied Sciences Mittweida, Laser Application Centre, \\ Technikumplatz 17, 09648 Mittweida, Germany \\ email: hartwig@htwm.de
}

\begin{abstract}
Intended for novel machining strategies in high power laser machining, a continuous wave single mode fibre laser (YLR-3000-SM, IPG) with a laser power up to $3 \mathrm{~kW}$ and a brilliant beam quality $\mathrm{M}^{2}<1.2$ has been applied in the presented work. Laser beam focusing was realised by industrial standard machining setups: large area scanning systems (RLSK; HighYAG), high speed scanning systems (Superscan; Raylase) and a stationary welding optic (YW50; Precitec). Laser welding of stainless steel has been investigated to compare significant interacting mechanism for different machining technologies. Butt joint welding and bead-on-plate welding have been applied under a range of various processing parameters, such as objective focal length, processing velocity, and laser output power. Ablation cutting on stainless steel and high-purity $\mathrm{Al}_{2} \mathrm{O}_{3}$ ceramics has been investigated subjected to various machining conditions. For discussion, the dependence of important laser processing parameters onto ablation depth has been indicated, and texture analyses show the material behaviour before and after the machining process.
\end{abstract}

DOI:10.2961/jlmn.2010.02.0006

Keywords: single mode fibre laser, continuous wave, high rate ablation, welding, remote cutting

\section{Introduction}

In recent years, application of fibre laser technology in deep penetration laser welding has been investigated. Applying $10 \mathrm{~kW}$ multi mode fibre lasers butt joint welding of metal sheets up to $10 \mathrm{~mm}$ thickness has been successfully established [1]. With high process velocities of $20 \mathrm{~m} / \mathrm{min}$ deep welding depths of $5 \mathrm{~mm}$ have been reached [2].

Presently, due to brilliant laser beam qualities of single mode fibre lasers with $\mathrm{M}^{2}=1.1$, small laser spot sizes can be realised resulting in deep penetration depths. Welding experiments with a $1 \mathrm{~kW}$ single mode fibre laser on stainless steel have shown the dependence of the penetration depth related to optimum focal spot size with aspect ratios up to 1:20 [3]. On the other hand, high speed laser cutting with process velocities of up to $100 \mathrm{~m} / \mathrm{min}$ has been applied in cutting of electro sheets using $\mathrm{CO}_{2}$ lasers with high beam qualities at high laser power [4].

Novel developments in laser scanner technologies, applicable in high power laser processing and coupled with high brilliant laser sources, such as fibre or disc lasers, enable the development of a direct high rate ablation technology. Due to strong material ablation no supplementary process gas is needed to blow out the molten material from cutting kerfs. In first investigations, the separation of thin metal sheets by using laser remote cutting technology has been successfully demonstrated [5].

The aim of this study was to investigate deep welding as soon as high speed welding processes by using high power brilliant fibre laser technology. To estimate process efficiencies, ablation rates and cutting depths of stainless steel and $\mathrm{Al}_{2} \mathrm{O}_{3}$ ceramics have been determined depending on focus spot size, laser power, and the quantity of over scans. Furthermore, micro cavities in stainless steel have been evaluated to discuss the applicability of high rate ablation technologies in laser micro processing.

\section{Experimental setup}

In this study, a continuous wave single mode fibre laser YLR-3000 SM (IPG) with maximal laser output power of $3 \mathrm{~kW}$, beam quality better than $\mathrm{M}^{2}=1.2$, and randomised beam polarisation has been applied. Beam deflection and focusing was implemented by two different high power scanning systems: a remote laser welding head RLSK (HighYAG) and a Superscan-SC-30-Y-Dig2 (Raylase). Focal distance of RLSK objective was $\mathrm{f}=500 \mathrm{~mm}$; Superscan was equipped with an objective focal distance of $\mathrm{f}=200 \mathrm{~mm}$.

Table 1 Process parameter scanning systems.

\begin{tabular}{|l|c|c|}
\hline Process parameter & $\boldsymbol{R L S K}$ & Superscan \\
\hline focal distance $[\mathrm{mm}]$ & 500 & 200 \\
\hline laser spot size $\mathrm{d}_{86}[\mu \mathrm{m}]$ & 78 & 21 \\
\hline max. scanning speed $[\mathrm{m} / \mathrm{min}]$ & 600 & 900 \\
\hline max. laser power at sample $[\mathrm{kW}]$ & 2.82 & 2.64 \\
\hline max. intensity at sample $\left[\mathrm{W} / \mathbf{c m}^{2}\right]$ & $5.9 * 10^{7}$ & $7.6 * 10^{8}$ \\
\hline min. dwell time $[\mu \mathrm{s}]$ & 7.8 & 1.4 \\
\hline
\end{tabular}

Table 2 Process parameter welding head YW50.

\begin{tabular}{|l|c|c|}
\hline Welding head $\mathbf{Y W} \mathbf{5 0}$ & objective 1 & objective 2 \\
\hline focal distance $[\mathrm{mm}]$ & 500 & 240 \\
\hline laser spot size $\mathrm{d}_{86}[\mathrm{\mu m}]$ & 109 & 57 \\
\hline max. processing speed $[\mathrm{m} / \mathrm{min}]$ & 120 & 120 \\
\hline max. laser power at sample $[\mathrm{kW}]$ & 3.0 & 3.0 \\
\hline max. intensity at sample $\left[\mathbf{W} / \mathbf{c m}^{2}\right]$ & $3.2 * 10^{7}$ & $1.1^{*} 10^{8}$ \\
\hline
\end{tabular}

Additionally, in welding experiments a welding head YW50 made by Precitec with 125 mm collimation length 
and focal distances of $240 \mathrm{~mm}$ and $500 \mathrm{~mm}$ was applied. The relative movement between sample and laser beam was realised by 3 axis positioning system. Significant process parameters have been summarised in table 1 and 2 .

\section{Experimental details}

Laser welding processes have been carried out on stainless steel X5CrNi 18-10 (AISI 304) metal sheets by means of laser line scans of $35 \mathrm{~mm}$ length focused onto the sample surface. At first, high speed laser welding with Superscan was performed on metal sheets of $1 \mathrm{~mm}$ thickness. Furthermore, deep penetration laser welding was studied using welding head YW50 and various focal distances (table 2) at stainless steel sheets of $20 \mathrm{~mm}$ thickness.

In deep penetration welding, machining speed was varied in a range between 0.5 to $10 \mathrm{~m} / \mathrm{min}$; in high speed laser welding the maximum processing speed was $200 \mathrm{~m} / \mathrm{min}$ respectively. However, at machining with higher process velocities a transition from laser welding to material ablation effects has been detected.

Additionally, high speed laser ablation has been investigated by using laser line scanning technology with line lengths up to $50 \mathrm{~mm}$ and various numbers of over scans. During the laser machining process a delay between separate over scans ensures a constant focus position onto the sample surface; otherwise a focus shift has been measured due to thermal lens effects at higher energy inputs.

The experiments show, for a stable ablation process the machining speed should be above a material specific minimum working speed. Therefore, the minimum scanning velocity thresholds depending on focus spot sizes have been summarised in table 3. Laser spot size of the RLSK system was $78 \mu \mathrm{m}$ and of Superscan was $21 \mu \mathrm{m}$ respectively.

Table 3 Processing speed threshold for ablation [m/min].

\begin{tabular}{|l|c|c|}
\hline Material & RLSK & Superscan \\
\hline X5CrNi 18-10 (AISI 304) & 500 & 300 \\
\hline $\mathrm{Al}_{2} \mathrm{O}_{3}$-Ceramic & 100 & n.a. \\
\hline
\end{tabular}

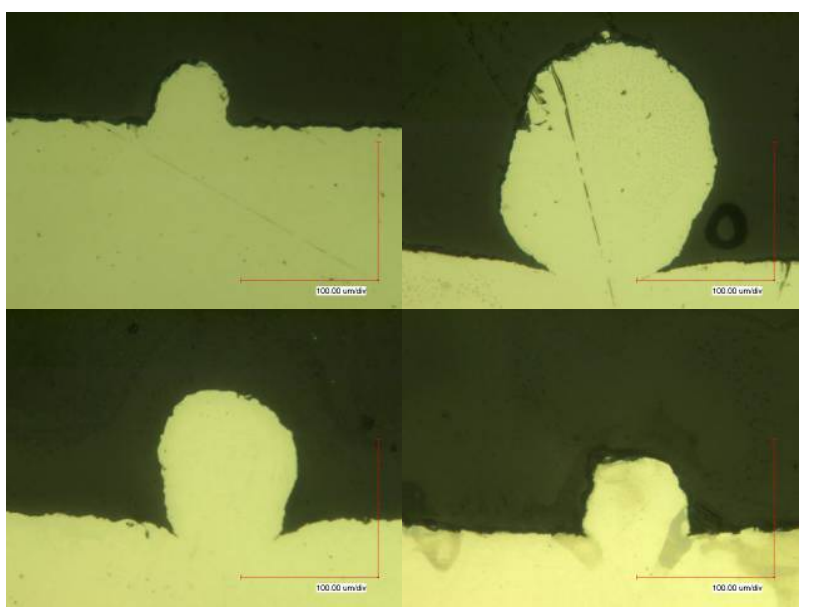

Fig. 1 Material bulges at stainless steel surface after laser welding using Superscan with $60 \mathrm{~m} / \mathrm{min}$ processing speed, laser power in $\mathrm{kW} /$ number of scans: a) 0.27/1, b) 0.27/5, c) 0.43/1, d) 0.62/1.

Laser machining of both, carbon steel and stainless steel below estimated processing speed thresholds has shown a strong melting with an insufficient blow out of the molten material. Therefore, figure 1 illustrates results obtained with a machining speed of $60 \mathrm{~m} / \mathrm{min}$; processing speed threshold was determined of $300 \mathrm{~m} / \mathrm{min}$. Instead of clear lines irregular structures were obtained. A further reduction of the processing speed led to deep penetration welding effects.

Comparably, processing of ceramics below processing speed thresholds shows strong material melting effects.

\section{Experimental results}

\subsection{Evaluation methods}

At different positions of the weld seams machining results have been evaluated by means of polished and etched cross sections perpendicular to the welding direction. Ablation and cutting depths of the steel texture have been determined by measuring the clear cross sectional area of the cutting depths using a digital light microscopy. The measured values varied in cutting depths and widths because of a redeposition and resolidification of the molten material within the cutting kerfs.

\subsection{Deep penetration welding at high processing speed}

In deep penetration welding, welding head YW50 has been applied. Experimental results using $240 \mathrm{~mm}$ focusing lens and velocities ranges up to $10 \mathrm{~m} / \mathrm{min}$ show deep penetration depths without any evidence of a significant dependence onto the processing speed (figure 2).

However, implementation of focusing lenses with short focal lengths has required a complex process handling because of extensive plasma plumes and otherwise short distances between focus position and objective. Already a small amount of ablated material deposited onto the lens protection glass, such as dust or debris, has destroyed the beam profile. Consequently a drop of welding depths has been detected as shown in figure 2 at $2 \mathrm{~kW}$ and $7.5 \mathrm{~m} / \mathrm{min}$. Implementation of a doubled cross jet and a permanent cleanness control of the lens protecting glass supplies constant machining conditions. Therefore deep welding depths have been obtained at high laser power of $3 \mathrm{~kW}$.

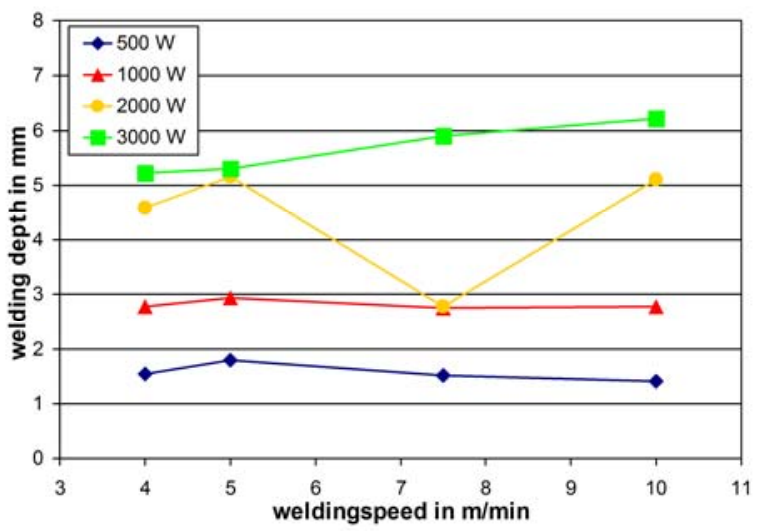

Fig. 2 Penetration depths vs. processing speed and laser power on stainless steel X5CrNi 8-10 (YW50; $240 \mathrm{~mm}$ focal distance).

Figure 3 illustrates cross sections of spiky bead-on-plate welds on stainless steel X5CrNi 8-10 (AISI 304) machined with welding head YW50, $240 \mathrm{~mm}$ focal distance, $3 \mathrm{~kW}$ laser power and increasing machining speed ( $5 \mathrm{~m} / \mathrm{min}, 7.5 \mathrm{~m} / \mathrm{min}, 10 \mathrm{~m} / \mathrm{min}$ ). Results show, at faster 
machining speed higher aspect ratios with deeper welding depths and smaller seam widths have been achieved.
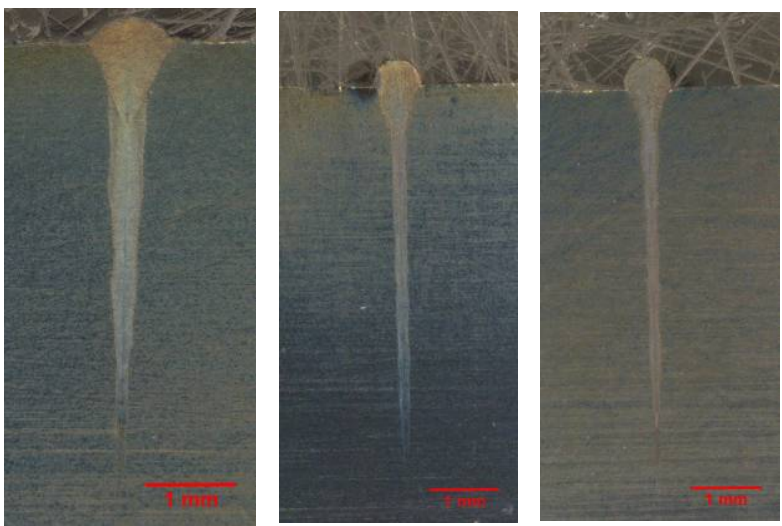

Fig. 3 Cross sections of bead-on-plate welds on stainless steel X5CrNi 8-10 (AISI 304) (YW50; $240 \mathrm{~mm}$ focal distance).

Left: laser power: $3 \mathrm{~kW}$; processing speed: $5 \mathrm{~m} / \mathrm{min}$; penetration depth and width: $5.3 \mathrm{~mm} / 0.2 \mathrm{~mm}$.

Centre: laser power: $3 \mathrm{~kW}$; processing speed: $7.5 \mathrm{~m} / \mathrm{min}$; penetration depth and width: $5.9 \mathrm{~mm} / 0.18 \mathrm{~mm}$.

Right: laser power: $3 \mathrm{~kW}$, processing speed: $10 \mathrm{~m} / \mathrm{min}$; penetration depth and width: $6.2 \mathrm{~mm} / 0.18 \mathrm{~mm}$.

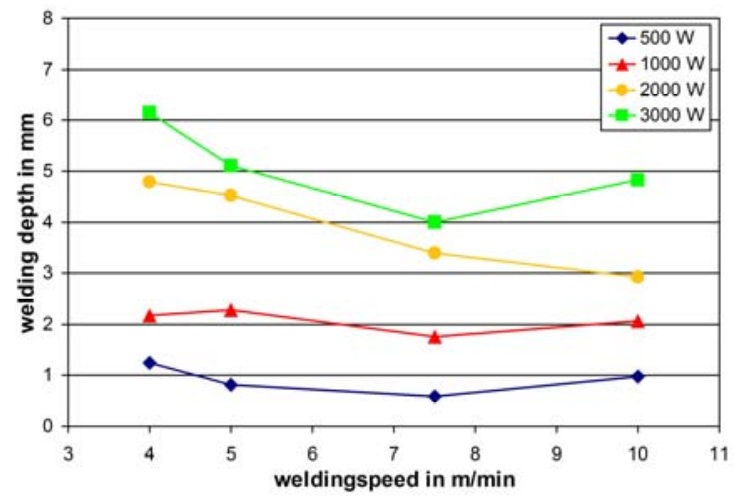

Fig. 4 Penetration depth vs. processing speed and laser power on stainless steel X5CrNi 18-10 (AISI 304) (YW50; 500 mm focal distance).
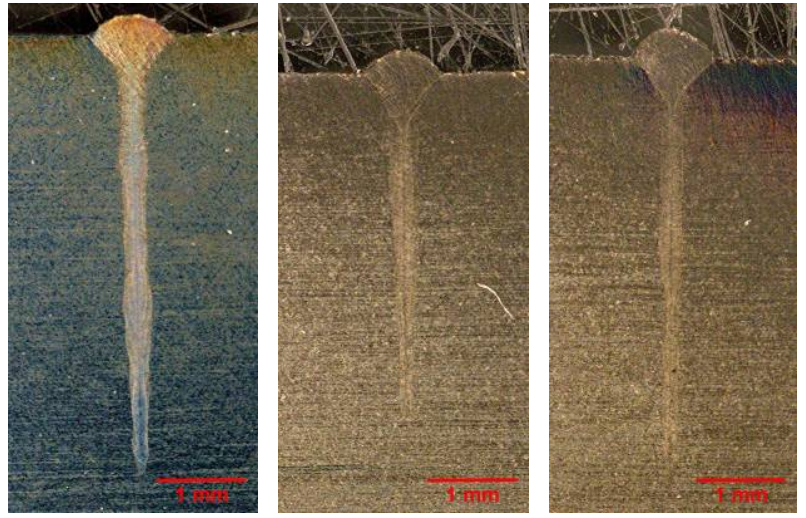

Fig. 5 Cross sections of bead-on-plate welds on stainless steel X5CrNi 18-10 (AISI 304) (YW50; $500 \mathrm{~mm}$ focal distance).

Left: laser power: $3 \mathrm{~kW}$; processing speed: $5 \mathrm{~m} / \mathrm{min}$; penetration depth and width: $5.1 \mathrm{~mm} / 0.24 \mathrm{~mm}$.

Centre: laser power: $3 \mathrm{~kW}$; processing speed: $7.5 \mathrm{~m} / \mathrm{min}$; penetration depth and width: $4.0 \mathrm{~mm} / 0.23 \mathrm{~mm}$.

Right: laser power: $3 \mathrm{~kW}$, processing speed: $10 \mathrm{~m} / \mathrm{min}$; penetration depth and width: $4.8 \mathrm{~mm} / 0.24 \mathrm{~mm}$.
Figure 4 summarises welding depths related to scanning speed and laser power, obtained with welding head YW50 and a large focal distance of $\mathrm{f}=500 \mathrm{~mm}$. Compared to welding results achieved with short focal distances, large objectives led to much smaller penetration depths. However, due to the larger distance between focusing objective and material surface, effort for lens cleaning has been decreased and consistent penetration depths have been obtained.

In figure 5, cross sections of slight and spiky welding seams machined with large focal distance of $500 \mathrm{~mm}$ are shown. At the same processing parameters, machining quality is comparable to results obtained with $240 \mathrm{~mm}$ objective; exceptionally aspect ratios have not been reached.

\subsection{Micro deep welding with highest processing speed}

Investigation of high speed micro deep welding has been accomplished onto $1 \mathrm{~mm}$ stainless steel metal plates with the Superscan system; focal distance was $200 \mathrm{~mm}$. Figure 6 indicates an inverse relation between penetration depth and processing speed; at higher laser power deeper welding depths have been measured. At first, with increased machining speed from $5 \mathrm{~m} / \mathrm{min}$ up to $180 \mathrm{~m} / \mathrm{min}$ considerable lowered welding depths have been obtained. For results obtained with processing speed faster or equal than $180 \mathrm{~m} / \mathrm{min}$, cross sections have shown a distinctive kerf development accompanied with ablation characteristics at the top of the welding seams. Within the velocity range of $180 \mathrm{~m} / \mathrm{min}$ to $240 \mathrm{~m} / \mathrm{min}$, a transition from welding to ablation mechanism has been derived, whereby transition area depends on incident laser power. However, using $620 \mathrm{~W}$ laser power and $30 \mathrm{~m} / \mathrm{min}$ processing speed the stainless steel plate has been welded through.

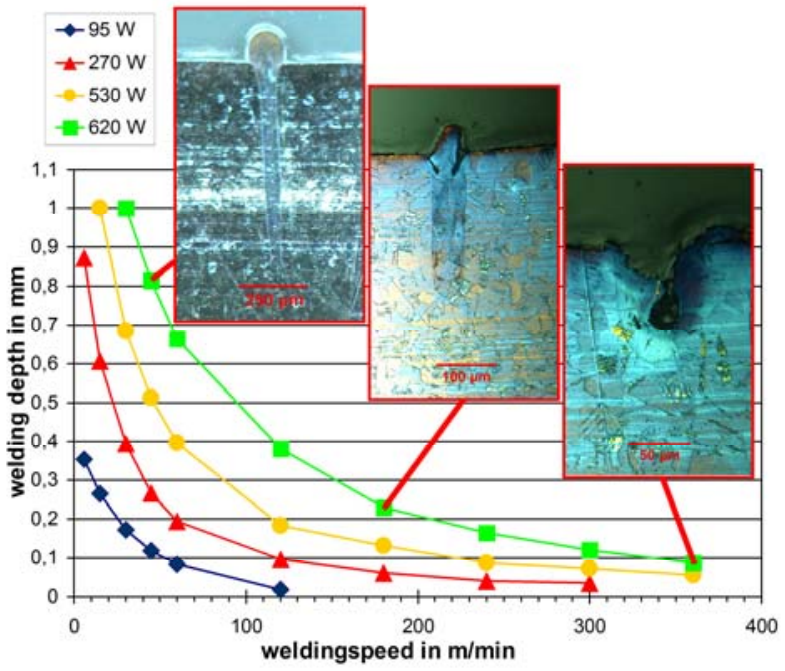

Fig. 6 Penetration depths vs. processing speed and laser power achieved at $1 \mathrm{~mm}$ thick stainless steel metal plate (X5CrNi 18-10 (AISI 304) ) by bead- on-plate welding with Superscan.

Cross sections of bead-on-plate welds on $1 \mathrm{~mm}$ stainless steel metal sheets illustrates figure 7 at various laser power and processing velocities. For high speed processing a welding through of the metal sheet has been obtained with $530 \mathrm{~W}$ at $15 \mathrm{~m} / \mathrm{min}$ or $620 \mathrm{~W}$ at $30 \mathrm{~m} / \mathrm{min}$ processing speed respectively. 

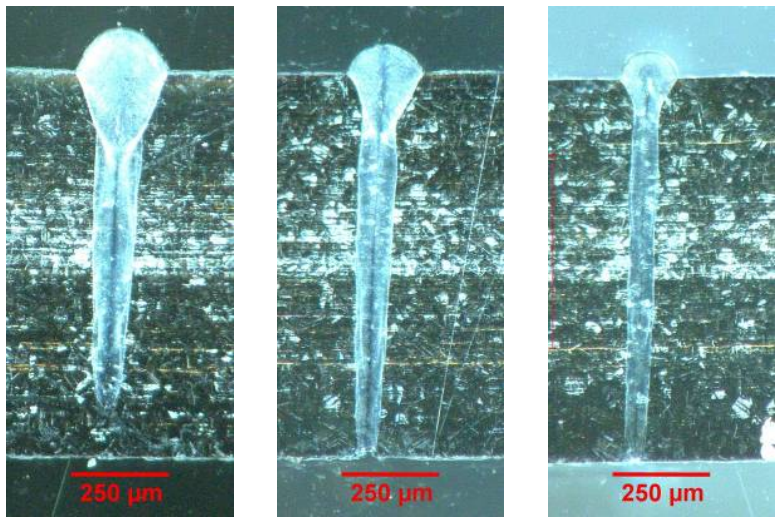

Fig. 7 Cross sections of bead-on-plate welds machined at various laser power and processing velocities.

Left: laser power: $270 \mathrm{~W}$, processing speed: $6 \mathrm{~m} / \mathrm{min}$.

Centre: laser power: $530 \mathrm{~W}$, processing speed: $15 \mathrm{~m} / \mathrm{min}$.

Right: laser power: $620 \mathrm{~W}$, processing speed: $30 \mathrm{~m} / \mathrm{min}$.

\subsection{Ablation cutting}

\subsubsection{Stainless steel X5CrNi 18-10 (AISI 304)}

Figure 8 illustrates ablation depth versus number of over scans for stainless steel ablation cutting with RLSK scanning system. The highest cutting depth was $500 \mu \mathrm{m}$, achieved with 10 over scans at $500 \mathrm{~m} / \mathrm{min}$ processing speed and maximal laser power of $2.82 \mathrm{~kW}$.

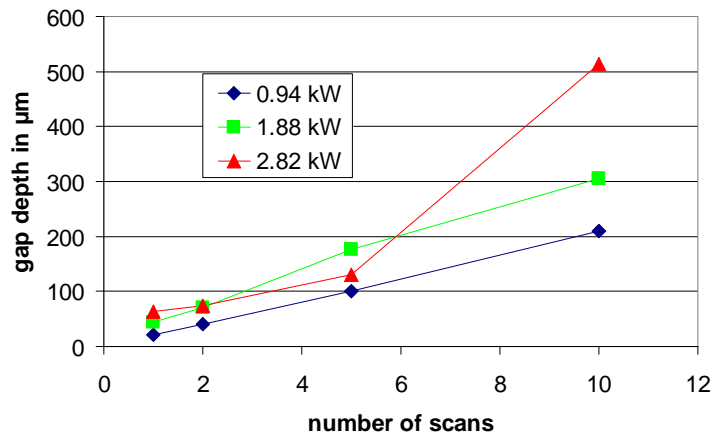

Fig. 8 Cutting depths vs. numbers of over scans and laser power in $0.6 \mathrm{~mm}$ thick stainless steel, processing speed: $500 \mathrm{~m} / \mathrm{min}$, RLSK.

For machining of stainless steel X5CrNi 18-10 (AISI 304) with Superscan and $500 \mathrm{~m} / \mathrm{min}$ processing speed, between 5 and 10 over scans an insignificant growth of the cutting depth is observable (figure 9).

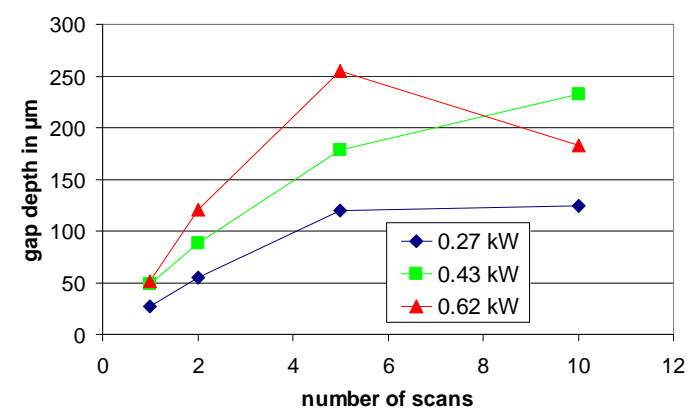

Fig. 9 Cutting depth vs. laser power and number of over scans in $0.6 \mathrm{~mm}$ thick stainless steel, scanning speed: $500 \mathrm{~m} / \mathrm{min}$, Superscan.

Furthermore a drop of cutting depth at laser power of $0.62 \mathrm{~kW}$ has been detected. Therefore too much laser energy was irradiated by either high laser power or repeatedly line scanning across the sample, and causes a massive material melting. The melting flows into the small cutting kerf and reduces or stops the cutting process.

Analyses of process efficiencies have shown for RLSK scanner at $500 \mathrm{~m} / \mathrm{min}$, an energy input of $600 \mathrm{~J} / \mathrm{m}$ was needed to achieve $100 \mu \mathrm{m}$ cutting depth. With increasing scanning speed of up to $600 \mathrm{~m} / \mathrm{min}$ only a minor change of the energy need has been detected. Consequently, a consistent ablation process independent from scanning speed and number of over scans can be assumed. Exceptionally, at either too high or too less laser power, a higher energy input per section was required to achieve ablation kerfs deeper than $50 \mu \mathrm{m}$.

Applying Superscan at processing speed of $500 \mathrm{~m} / \mathrm{min}$, only $120 \mathrm{~J} / \mathrm{m}$ energy input per section has been calculated to ablate $100 \mu \mathrm{m}$ in depth. Thus, machining with higher laser intensity due to smaller focus spot size applying Superscan, ablation process was up to 5 times more efficient. Because of the observed stable cutting process at high scanning velocities, complementary experiments has been performed with Superscan and up to $900 \mathrm{~m} / \mathrm{min}$ machining speed. The results summarises figure 10 .

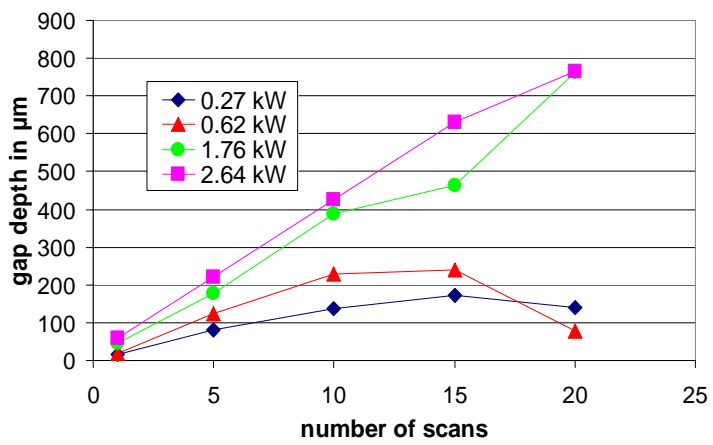

Fig. 10 Cutting depth vs. number of over scans and laser power in $0.6 \mathrm{~mm}$ thick stainless steel, processing speed: $900 \mathrm{~m} / \mathrm{min}$, Superscan.

The plot shows a repeatable ablation process up to 5 over scans. Within 5 test series a maximum deviation of $3 \%$ in cutting depths has been detected. However, compared to $500 \mathrm{~m} / \mathrm{min}$ processing speed, much higher laser power was irradiated to achieve deep ablation depths. It indicates a non-linear decrease of process efficiency.

To cut through a metal sheet of $0.5 \mathrm{~mm}$ thickness, the achieved cumulated cutting speed of $75 \mathrm{~m} / \mathrm{min}$ is much higher than the maximum of $60 \mathrm{~m} / \mathrm{min}$, reported in remote cutting experiments [6].

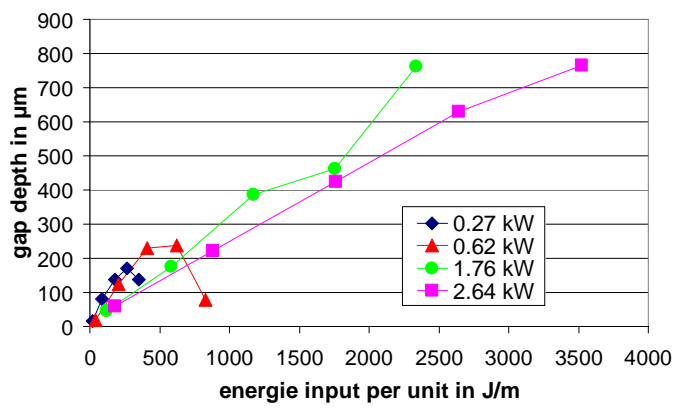

Fig. 11 Cutting depth depending on energy input per unit section in $0.6 \mathrm{~mm}$ thick stainless steel, processing speed: $900 \mathrm{~m} / \mathrm{min}$, Superscan. 
Figure 11 shows the laser energy per unit section related to cutting depths by using Superscan and $900 \mathrm{~m} / \mathrm{min}$ machining velocity. To ablate $100 \mu \mathrm{m}$ with a little laser power of $270 \mathrm{~W}$, the estimated energy need per section of $100 \mathrm{~J} / \mathrm{m}$ was lesser than $120 \mathrm{~J} / \mathrm{m}$ achieved for $500 \mathrm{~m} / \mathrm{min}$. On other hand, processing with high laser power (2.64 kW) shows an increasing energy need per section $(425 \mathrm{~J} / \mathrm{m})$, and signifies a lesser process efficiency at higher laser power. However, in the plot deep cutting kerfs at consistent process conditions as main advantage of high power laser processing are clearly recognisable.

Furthermore, ultra high speed photographs show the development of stronger process plasma at higher laser power, and can be assumed for the higher energy need at machining with high laser power.

As illustrated in figure 12, high power laser machining with suitable processing parameters results in neglected heat affected zones; widths of generated micro structures have been achieved with less than $10 \mu \mathrm{m}$ and aspect ratios up to $1: 10$. In stainless steel the ablation rates vary between 15 and $40 \mathrm{~mm}^{3} / \mathrm{s}$ and ablation rates decrease with higher number of over scans and less laser power.

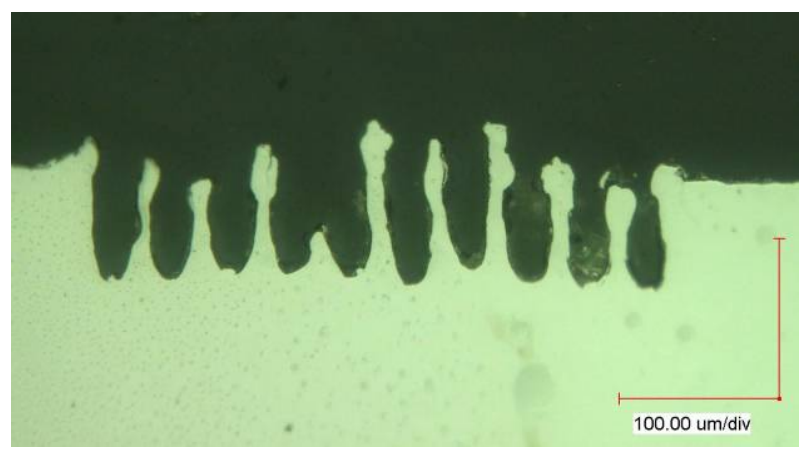

Fig. 12 Micro ablation in stainless steel, laser power: $0.27 \mathrm{~kW}$ processing speed: $900 \mathrm{~m} / \mathrm{min}$, hatch distance: $37 \mu \mathrm{m}$, 4 over scans, Superscan.

\subsection{2 $\mathrm{Al}_{2} \mathrm{O}_{3}$ - Ceramics}

Figure 13 illustrates an ablation result in $\mathrm{Al}_{2} \mathrm{O}_{3}$ ceramics. Laser machining with high laser power and fast scanning velocities (faster $400 \mathrm{~m} / \mathrm{min}$ ) resulted in melt free and crack free micro ablation. Otherwise machining with low scanning speed led to a slightly molten material deposition.

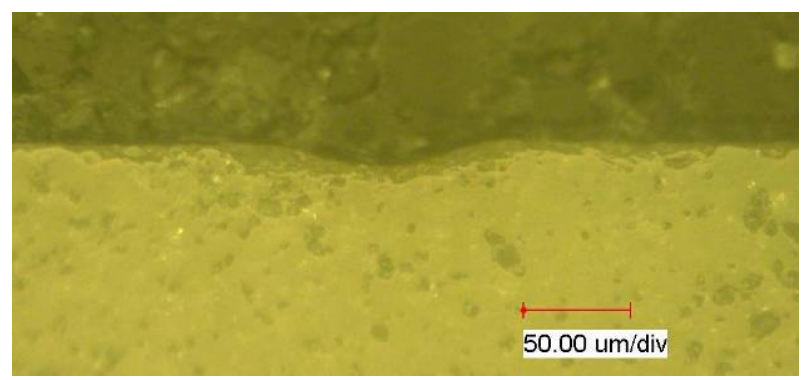

Fig. $1311 \mu \mathrm{m}$ deep micro ablation in $\mathrm{Al}_{2} \mathrm{O}_{3}$ ceramics, scanning speed: $600 \mathrm{~m} / \mathrm{min}$, laser power: $0.94 \mathrm{~kW}$, RLSK.

However, separation of ceramic sheets of $1 \mathrm{~mm}$ thickness have been realised with 10 over scans at laser power ranging from $0.92 \mathrm{~kW}$ to $2.35 \mathrm{~kW}$ and $100 \mathrm{~m} / \mathrm{min}$ processing speed. Results of cut through experiments obtained with $2.35 \mathrm{~kW}$ laser power and varying processing speed have been summarised in figure 14. Ablation process shows two different interaction characteristics. Initially, within 5 scans only $100 \mu \mathrm{m}$ up to $300 \mu \mathrm{m}$ of the material thickness has been ablated. Within the next 5 over scans ablation rate increases considerably and it was possible to cut through the ceramic sheet. The growth of the ablation rate after 5 over scans was caused by an efficient incoupling of the laser beam in deeper regions through transparent melting zones.

Compared to stainless steel laser cutting a significant higher energy need has been required. To achieve a $100 \mu \mathrm{m}$ cutting kerf with $300 \mathrm{~m} / \mathrm{min}$ processing speed, an energy input of $1000 \mathrm{~J} / \mathrm{m}$ has been applied. Machining with suitable laser parameters the energy need per section has been halved to $500 \mathrm{~J} / \mathrm{m}$ for $100 \mu \mathrm{m}$ cutting depth. Achieved ablation rate between 15 and $20 \mathrm{~mm}^{3} / \mathrm{s}$ was approximately the half of the rates obtained on stainless steel.

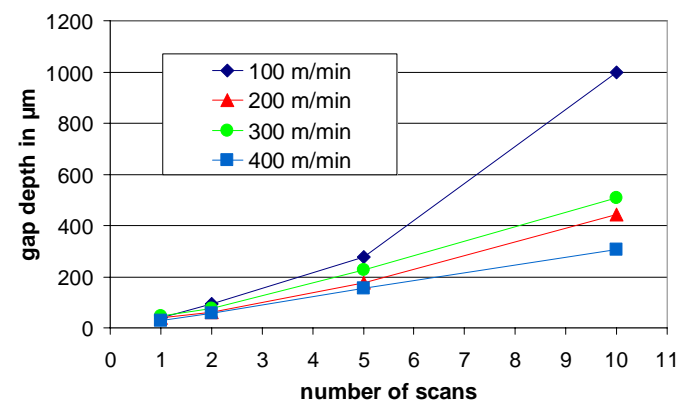

Fig. 14 Cutting depth vs. number of over scans on $\mathrm{Al}_{2} \mathrm{O}_{3^{-}}$ ceramics $1 \mathrm{~mm}$ thickness, laser power: $2.35 \mathrm{~kW}$, RLSK.

\subsection{Generation of micro cavities}

Generation of micro cavities applying high rate ablation technology has been successfully investigated on stainless steel X5CrNi 18-10 (AISI 304) by scanning line by line and layer by layer. Investigated machining parameters were laser power, numbers of over scans and hatch distance. Ablation depth per scan was comparable to results described in 4.2.2 for varying laser power. Quality of ablated surface was mainly influenced by the hatch distance, investigated in the range from $10 \mu \mathrm{m}$ up to $40 \mu \mathrm{m}$.

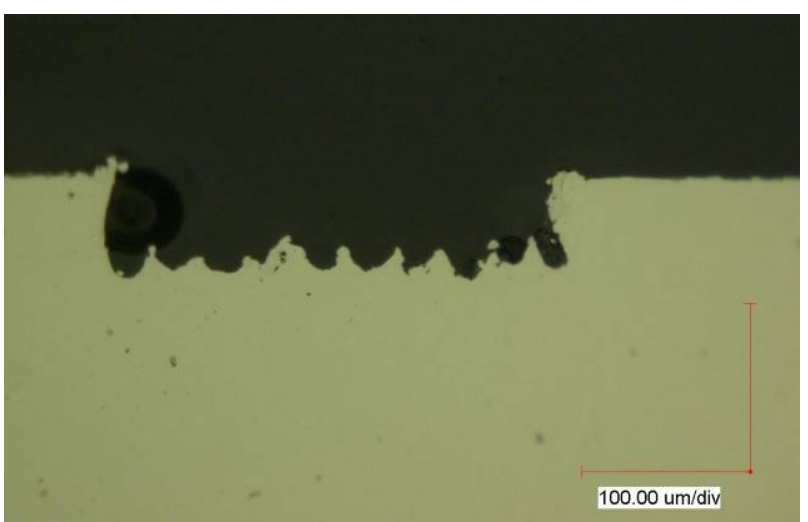

Fig. 15 Micro cavity in stainless steel X5CrNi 18-10 (AISI 304), laser processing speed: $900 \mathrm{~m} / \mathrm{min}$, laser power: $0.27 \mathrm{~kW}$, hatch distance: $29 \mu \mathrm{m}$; 4 over scans, Superscan.

Figure 15 illustrates a micro cavity with sharp edges and appropriate surface qualities fabricated with 10 parallel 
lines and a hatch distance of $29 \mu \mathrm{m}$. Cavity widths has been measured of $260 \mu \mathrm{m}$ at a depth of $50 \mu \mathrm{m}$ respectively.

\section{Conclusion and future work}

In this study, high brilliant high power continuous wave laser radiation and novel scanning technologies have been investigated to demonstrate applications in high speed laser processing of stainless steel and ceramics.

In high speed laser welding spiky weld seams with high aspect ratios have been achieved. Furthermore, penetration depths decrease with higher processing speed, and transition into material ablation has been observed. However, the small weld seam size meets challenges in welding process related to work piece positioning and fixation. Because of the high process efficiency and particularly spiky weld seams, substitution of electron-beam welding in future applications might be possible.

Furthermore, to investigate welding of high reflective materials, overlap welding processes, as soon as development of alternative beam alignment and beam switching will be future challenges.

In high rate laser ablation, cutting of stainless steel and ceramics with high processing velocities and negligible heat affected zones has been successfully demonstrated. Ablation depths with Superscan have been achieved up to 3.7 times deeper compared to RLSK scanner at similar laser power (figure 16) and correlate to the relation between focus spot diameters (78 $\mu \mathrm{m}$ vs. $21 \mu \mathrm{m})$. Respectively, a smaller focus spot diameter causes not only a squared increase of the intensity, but also a linearly decrease of the laser dwell time [7]. Concerning the ablation behaviour using smaller focus spot sizes, higher intensities lead to deeper cutting kerfs accompanied by shorter dwell times resulting in flatter cutting kerfs.

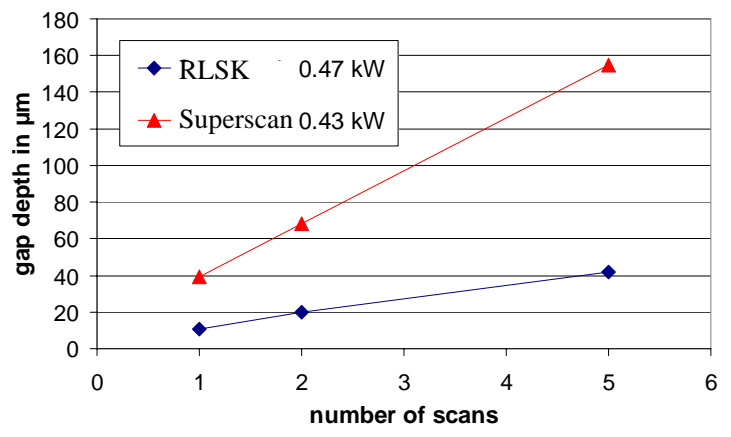

Fig. 16 Cutting depths vs. number of over scans and scanning system at similar laser power input on stainless steel X5CrNi 1810 (AISI 304) , processing speed: $600 \mathrm{~m} / \mathrm{min}$.
Future investigations aim to increase laser process velocities to analyse energy input per unit by machining with high laser power. Scanning velocities of up to 12,000 $\mathrm{m} / \mathrm{min}$ are possible to use by applying novel polygon scanning technologies.

Furthermore, in complementary investigations varied focusing lenses and focal lengths will be studied to optimise relations between laser power and intensity for enhanced machining qualities.

\section{Acknowledgement}

The authors gratefully acknowledge financial support of the presented work by the 'Bundesministerium für Bildung und Forschung’ (project number 03IP506).

\section{References}

[1] Ulf Jasnau, Reiner Gaede: Hochleistungsfaserlaser im Schiffbau, Laser Technik Journal 2/2008, Maerz 2008, pp. 30 - 33; (written in German).

[2] C. Thomy, T. Seefeld, F. Vollertsen: Schweißen mit Hochleistungs-Faserlasern, Laser Technik Journal 3/2005, September 2005, pp. 28 - 31; (written in German).

[3] Sonja Kittel: Welding with brilliant lasers - prospects and limitation for industrial application, 4th International Workshop on Fiberlasers, November 5 and 6 2008, Fraunhofer IWS Dresden.

[4] Preissig, K.U., Petring, D., Herziger, G.: High speed laser cutting of thin metal sheets, Laser Materials Processing - Industrial and Microelectronics Applications: 5-8 April 1994, Vienna, Austria. Bellingham/Wash.: SPIE, 1994. (Europto series), pp. $96-110$.

[5] Beyer, E., Himmer, T., Luetke, M.: RemoteSchneiden mit brillanten Strahlquellen, Münchener Kolloquium - Innovationen für die Produktion: Produktionskongress, 9. Oktober 2008; Tagungsband 2008, pp. 361 - 370; (written in German).

[6] D. Petring: Calculable Laser Cutting, Proceedings of the fifth International WLT-Conference on Lasers in Manufacturing, LIM 2009, 15.-18.6.2009, Munich, Germany, pp. 209 - 214.

[7] W. Suder, S. Williams, P. Colegrove: Absolute spot size effect on penetration depth in laser welding, Proceedings of the fifth International WLTConference on Lasers in Manufacturing, LIM 2009, 15.-18.6.2009, Munich, Germany, pp. 53 - 58.

(Received: July 24, 2009, Accepted: April 12, 2010) 